ISSN: 2224-0616

Int. J . Agril. Res. Innov. \& Tech. 4 (1): 44-52, J une, 2014

Available online at http:// www.ijarit.webs.com

\title{
CHANGES IN SEED WEIGHT IN RESPONSE TO DIFFERENT SOURCES: SINK RATIO IN OILSEED RAPE
}

\author{
Francisco M. Iglesias ${ }^{1}$ and Daniel J. Miralles ${ }^{1,2 *}$
}

\author{
Received 29 January 2014, Revised 30 May 2014, Accepted 28 June 2014, Published online 30 June 2014
}

\begin{abstract}
Little knowledge exists about the degree of source, sink and source: sink limitations on mean seed weight in oilseed rape (Brassica napus L.). The objective of this work was to analyze the nature and magnitude on seed weight response to assimilate availability during the effective seed-filling period in oilseed rape. Three Argentinean varieties, Eclipse, Impulse, and Master, were grown under field conditions, and at the beginning of the effective seed filling period, a broad range of source: sink manipulation combinations were produced. Source manipulations consisted of two incoming radiation (R) level reductions: $0 \%(\mathrm{Rn})$ and $\sim 50 \%$ (Rs) combined with three different sources: sink treatments were applied: C, control; PR, $\sim 50 \%$ pod removal, and D, 100\% defoliation. Rs significantly reduced yield (15\%) and MSW (12\%) with respect to $\mathrm{Rn}$, without significant effects on the rest of the sub yield components. Source:sink manipulation treatments significantly affected all yield components. PR diminished yield by $29 \%$, reducing ca. $40 \%$ seeds $\mathrm{l}^{-1}$ by reductions pods $\mathrm{pl}^{-1}(41 \%)$ with respect to Rn, whereas PR increased MSW by $19 \%$, counterbalancing the reduction in seeds $\mathrm{pl}^{-1}$ and thereby in yield. When considering different seed positions along the main raceme, Rs reduced MSW by $12 \%$ independently of seed positions onto the raceme. On the contrary, PR increased MSW in average 17\% with respect to C. Results reported here suggest that oilseed rape has source: sink co-limitation during the effective seed filling period, which is apparently higher than wheat and lower than maize.
\end{abstract}

Keywords: Seed Weight; Seed Number; Source: Sink Ratio; Oilseed Rape

${ }^{1}$ Cátedra de Cerealicultura, Dto. Producción Vegetal, Facultad de Agronomía UBA, Av San Martín 4453 (C1417DSE) Buenos Aires, Argentina; ${ }^{2}$ CONICET and IFEVA

*Corresponding author's email: miralles@agro.uba.ar (Daniel J. Miralles)

\section{Introduction}

The process of yield production can be interpreted as the balance between the source and sink activity during the reproductive period. This simple view involves the production of assimilates by the photosynthetic organs (source) and the utilization of these assimilates by the seeds (sink) (Egli, 1998). Seed number per unit area, the yield component that accounts for most of the variations in yield of grain crops (Peltonen-Sainio and Jauhiainen, 2008), is directly limited by the availability of assimilates produced during flowering and pod set by canopy photosynthesis (Keiller and Morgan, 1988). As seed number is defined during that period, it could be considered as the critical time in terms of yield, since source limitations during the period immediately after flowering will determine reductions in the number of seed established by the crop (Diepenbrock, 2000; Berry and Spink, 2006).

Final mean seed weight (MSW) depends on the relationships between the sink capacity and the availability of assimilates to fill this sink (J enner et al., 1991). Variations in MSW contribute in a lower range to variations in yield, being the source:sink ratio the major factor of this variation (Jullien et al., 2011). In oilseed rape, canopy photosynthesis activity declines rapidly during the effective seed-filling period (Gabrielle et al., 1998), and current photosynthesis from pods (Müller and Diepenbrock, 2006) becomes more important than leaves from mid to late reproductive phase. Some evidence, obtained under controlled conditions, showed that when source:sink ratio was reduced, MSW decreased between 10 and $25 \%$ depending on the degree of source limitations (Pechan and Morgan, 1985). These findings support the statement that oilseed rape could be source limited during the effective seed-filling period. Nevertheless, these results may not be directly extrapolated to field situations. This is because gradual source limitations along main stem could occur and be more severe at the canopy scale than in isolated plants due to the reduction of the incoming radiation at lower sections of pod and leaf canopy with respect to those at upper sections (Yates and Steven, 1987; Leach et al., 1989). 
Although in the literature has been reported source limitation in various crops and its impact on MSW (Borrás et al., 2004). Little knowledge exists about the nature and magnitude on MSW response to assimilate availability during the effective seed-filling period in oilseed rape. Lack of information is especially evident about the effects of changes in source: sink ratio on seeds in different sections within the main raceme and primary branches in field-grown plants. The objective of this work was to evaluate the sourcesink limitations during effective seed-filling period, analyzing seed growth and final seed weight responses into a broad range of assimilate supply per seed in three field grown canola varieties.

\section{Materials and Methods}

A field experiment was conducted at the experimental field of the Department of Plant Production (Faculty of Agronomy) of the

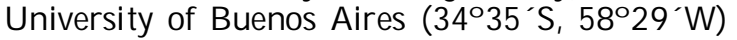
during the 2003 growing season. The soil was a silty clay loam type, classified as Vertic Argiudoll, according to the USDA taxonomy. Three oilseed rape Argentinean varieties (Eclipse, Impulse and Master) sown on $3^{\text {rd }} \mathrm{J}$ une, were subjected to different radiation and source: sink manipulations. Thus, treatments consisted of a combination of varieties, two radiation levels and three levels of source: sink manipulation. Crops were grown without water and nutriment limitations and protected during the whole crop cycle against weeds, insects and diseases. Plant density was $100 \mathrm{pl} / \mathrm{m}^{2}$ at emergence and the dimension of the plots was $2.5 \mathrm{~m}^{2}$ ( 7 rows, $0.15 \mathrm{~m}$ apart and $2.5 \mathrm{~m}$ long).

Shadow treatment (Rs) was imposed by black nylon shade from flowering to physiological maturity. Source: sink manipulation treatments were: i) control (C); ii) sink reduction, in which $50 \%$ of pods were alternately removed from the main raceme and branches (PR) in order to produce $50 \%$ reduction in the number of seeds per plant and iii) total defoliation (D). The different source: sink balance combinations were imposed at the beginning of the effective seedfilling period (i.e. $\mathrm{G}_{3}$ stage according to the scale of INRA-CETIOM, 1985). Thus, assimilate availability per seed was expected to be increased or reduced.

The experimental design used was a split-splitplot design with three replications, where the main factor was the genotype. Sub-plots consisted of two radiation levels: i) Control without restrictions of natural incident radiation (Rn) and ii) shadow treatment reducing $48 \%$ of incident radiation (Rs) and sub-sub-plots corresponding to the source: sink manipulation treatment combinations (Rn-C, Rn-PR, Rn-D, Rs-C, Rs-PR and Rs-D).
Weight of seeds during grain filling period was determined twice weekly from $\mathrm{G}_{2}$ stage (INRACETIOM, 1985) to maturity for seeds from specific sections within the main raceme and for seeds of pooled pods from all branches. The dynamics of grain weight for different positions within each source:sink ratio treatment was followed in 20 uniform plants per replication per sampling date randomly selected and tagged at onset of flowering from the central rows of each sub-sub-plot. Pods were selected to represent different sections within the main raceme as follows: (i) lower, (ii) middle and (iii) upper pod positions. Seeds from branches were pooled sampled. In each sample, seeds from selected positions described above were oven-dried and weighed separately. Mean seed weight was determined by randomly weighting a sample of 100 seeds, three times, for each replication. These data were used to determine the physiological components of MSW (i.e. rate and duration of grain filling).

The dynamics of seed filling from $\mathrm{G}_{2}$ onwards were fitted by a bilinear model (see equation 1) and the rate and duration (total and effective duration) calculated for seeds of different sections and treatments into the plant.

MSW $=a+b^{*} x(x \leq c)+b^{*} c(x \geq c)$

In this model, $b$ represents the seed growth rate during the effective seed-filling period $\left(\mathrm{mg}^{\circ} \mathrm{Cd}^{-1}\right)$ and $\mathrm{c}$, the duration of the effective seed-filling period $\left({ }^{\circ} \mathrm{Cd}\right)$. The bilinear model was fitted to the seed dry weight data using iterative optimization techniques applying Table Curve V3 (Jandel Scientific 1992). Daily thermal time (TT) values were calculated considering the mean daily temperature minus the base temperature of 4.5으 (Mendham et al., 1981).

At physiological maturity, 10 plants within each sub-sub-plot were harvested. The samples were oven-dried and yield per plant, seed number per plant, number of seeds per pod and average seed weight were determined.

\section{Results}

\section{Radiation and source: sink alteration on yield and its components}

The main effects (i.e. genotype- $G$, radiation- $R$ (Rn and Rs) and source: sink ratio-SS) differentially modified yield and its components. Regarding the genotypic differences, Eclipse showed the highest yield $(3.4 \mathrm{~g} / \mathrm{pl})$, followed by Master $(3.1 \mathrm{~g} / \mathrm{pl})$ and Impulse $(2.8 \mathrm{~g} / \mathrm{pl})$. A similar trend was shown by seed/pl and seed/pod. Contrary to what was observed in yield and seeds/pl, Eclipse registered the lowest MSW $(2.8 \mathrm{mg} / \mathrm{seed}$, with respect to Impulse and Master (3.4 mg/ seed) (Table 1). 
Table 1. Effects of genotype, source:sink ratio (control, C; pod removal, PR; and defoliation, D) and radiation levels ( $100 \%, \mathrm{Rn}$; and $48 \%$, Rs, of incident radiation) on yield components

\begin{tabular}{|c|c|c|c|c|c|c|c|c|c|c|c|c|c|c|c|c|c|}
\hline \multirow{2}{*}{$\begin{array}{l}\text { Genotype } \\
\text { Eclipse }\end{array}$} & \multirow{2}{*}{\begin{tabular}{|c|} 
Radiation \\
$\mathrm{Rn}$
\end{tabular}} & \multirow{2}{*}{$\begin{array}{c}\mathrm{S}: \mathrm{S} \\
\mathrm{C}\end{array}$} & \multicolumn{3}{|c|}{ Yield/pl } & \multicolumn{3}{|c|}{ Seeds/pl } & \multicolumn{3}{|c|}{ MSW } & \multicolumn{3}{|c|}{ Seeds/pod } & \multicolumn{3}{|c|}{ Pods/pl } \\
\hline & & & 4265 & \pm & 375 & 1525 & \pm & 121 & 2.79 & \pm & 0.06 & 17,6 & \pm & 0,41 & 86 & \pm & 5,0 \\
\hline & & PR & 2992 & \pm & 383 & 904 & \pm & 101 & 3.30 & \pm & 0.10 & 17,3 & \pm & 1,26 & 52 & \pm & 2,4 \\
\hline & & $\mathrm{D}$ & 3452 & \pm & 39 & 1164 & \pm & 25 & 2.97 & \pm & 0.04 & 14,5 & \pm & 0,58 & 80 & \pm & 1,7 \\
\hline & Rs & $\mathrm{C}$ & 3503 & \pm & 280 & 1396 & \pm & 156 & 2.52 & \pm & \begin{tabular}{|l|}
0.11 \\
\end{tabular} & 17,0 & \pm & 1,99 & 82 & \pm & 0,8 \\
\hline & & PR & 2816 & \pm & 194 & 952 & \pm & 79 & 2.96 & \pm & 0.05 & 17,9 & \pm & 2,17 & 53 & \pm & 2,2 \\
\hline & & $\mathrm{D}$ & 3079 & \pm & 485 & 1231 & \pm & 234 & 2.52 & \pm & 0.11 & 16,1 & \pm & 0,59 & 77 & \pm & 13,5 \\
\hline \multirow[t]{6}{*}{ Impulse } & $\mathrm{Rn}$ & $\mathrm{C}$ & 3558 & \pm & 75 & 1058 & \pm & 25 & 3.37 & \pm & 0.12 & 15,9 & \pm & 0,05 & 66 & \pm & 1,6 \\
\hline & & PR & 2220 & \pm & 197 & 556 & \pm & 97 & 4.08 & \pm & 0.40 & 15,0 & \pm & 2,15 & 37 & \pm & 1,4 \\
\hline & & $\mathrm{D}$ & 3326 & \pm & 420 & 993 & \pm & 134 & 3.36 & \pm & 0.10 & 14,6 & \pm & 0,90 & 68 & \pm & 8,3 \\
\hline & Rs & $\mathrm{C}$ & 2987 & \pm & 150 & 997 & \pm & 77 & 3.00 & \pm & 0.11 & 14,4 & \pm & 0,44 & 69 & \pm & 3,2 \\
\hline & & PR & 2121 & \pm & 81 & 585 & \pm & 32 & 3.64 & \pm & 0.25 & 15,9 & \pm & 1,03 & 37 & \pm & 0,5 \\
\hline & & $\mathrm{D}$ & 2636 & \pm & 100 & 905 & \pm & 24 & 2.91 & \pm & 0.04 & 14,7 & \pm & 0,32 & 62 & \pm & 2,9 \\
\hline \multirow[t]{6}{*}{ Master } & $\mathrm{Rn}$ & $\mathrm{C}$ & 4030 & \pm & 521 & 1194 & \pm & 183 & 3.40 & \pm & \begin{tabular}{|l|}
0.16 \\
\end{tabular} & 17,2 & \pm & \begin{tabular}{|l|}
0,58 \\
\end{tabular} & 69 & \pm & 8,9 \\
\hline & & PR & 2867 & \pm & 40 & 713 & \pm & 16 & 4.02 & \pm & 0.06 & 17,9 & \pm & 0,56 & 40 & \pm & 0,5 \\
\hline & & $\mathrm{D}$ & 3293 & \pm & 247 & 1017 & \pm & 79 & 3.24 & \pm & 0.06 & 16,1 & \pm & 0,72 & 63 & \pm & 5,1 \\
\hline & Rs & $\mathrm{C}$ & 3437 & \pm & 68 & 1157 & \pm & 32 & 2.98 & \pm & 0.14 & 16,6 & \pm & 1,23 & 70 & \pm & 3,3 \\
\hline & & $\overline{P R}$ & 2437 & \pm & 263 & 689 & \pm & 42 & 3.52 & \pm & \begin{tabular}{|l|}
0.17 \\
\end{tabular} & 17,3 & \pm & 0,29 & 40 & \pm & 3,0 \\
\hline & & $\mathrm{D}$ & 2379 & \pm & 214 & 807 & \pm & 55 & 2.94 & \pm & 0.06 & 14,2 & \pm & 0,87 & 57 & \pm & 0,5 \\
\hline Genotype (G) & & & \multicolumn{3}{|c|}{ ** } & \multicolumn{3}{|c|}{$*$} & \multicolumn{3}{|c|}{ ** } & \multicolumn{3}{|c|}{$\mathrm{NS}$} & \multicolumn{3}{|c|}{ *** } \\
\hline Radiation (R) & & & \multirow{2}{*}{\multicolumn{3}{|c|}{$* *$}} & \multirow{2}{*}{\multicolumn{3}{|c|}{$\frac{\mathrm{NS}}{* * *}$}} & & ** & & \multicolumn{3}{|c|}{$\begin{array}{l}\text { NS } \\
* * *\end{array}$} & \multicolumn{3}{|c|}{ NS } \\
\hline \multicolumn{2}{|c|}{ Source: sink (SS) } & & & & & & & & \multicolumn{3}{|c|}{ *** } & & & & & **** & \\
\hline$\overline{\mathrm{G} \times \mathrm{R}}$ & & & \multicolumn{3}{|c|}{ NS } & \multicolumn{3}{|c|}{ NS } & \multicolumn{3}{|c|}{ NS } & \multicolumn{3}{|c|}{ NS } & \multicolumn{3}{|c|}{$\mathrm{NS}$} \\
\hline $\mathrm{G} \times \mathrm{SS}$ & & & \multicolumn{3}{|c|}{ NS } & & NS & & & NS & & & $\overline{\mathrm{JS}}$ & & & NS & \\
\hline$\overline{\mathrm{SS}} \times \mathrm{R}$ & & & & NS & & & NS & & & NS & & & JS & & & NS & \\
\hline $\mathrm{G} \times \mathrm{R} \times \mathrm{SS}$ & & & & NS & & & $\overline{N S}$ & & & NS & & & $\overline{\mathrm{JS}}$ & & & NS & \\
\hline
\end{tabular}

*, **, ***: significant at 0.05, 0.01 and 0.001 probability level, respectively, and NS: not significant.

The Rs treatment significantly reduced yield (15\%) and MSW (12\%), with respect to Rn, without significant effects on the rest of the sub yield components. There was not any $\mathrm{G} x \mathrm{R}$ interaction, demonstrating that Rn similarly affected all the genotypes (Table 1).

Source: sink manipulations significantly affected all yield components. Thus, PR diminished yield by $29 \%$ as a consequence of reductions of ca. $40 \%$ in the seeds/pl and pods/pl (41\%), respect to the $\mathrm{C}$ treatment. The yield component seeds/ pod was not affected by PR. Conversely that was observed in the number of seeds, the PR treatment increased MSW ca 19\%, counterbalancing, although partially, the reduction in seeds/ $\mathrm{pl}$ and thereby, the yield reduction was less than that observed in the latter yield component (Table 1, Fig. 1). The D treatment reduced yield, although the magnitude was less than that observed in PR, as D reduced yield $19 \%$ with respect to $\mathrm{C}$. The $17 \%$ reduction observed in seeds/pl in D was produced by a diminished seeds/pod and pod/pl of ca. $9 \%$ in each yield component (Table 1, Fig. 1).

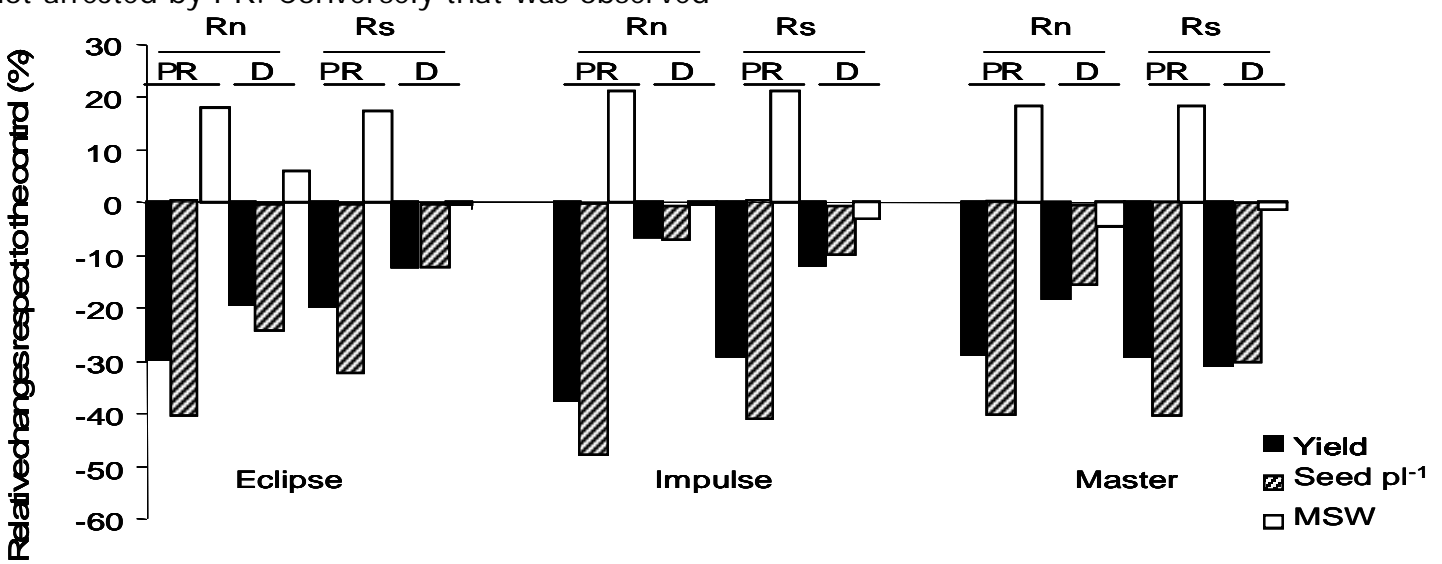

Fig. 1. Relative changes in yield per plant, seed number per plant and mean seed weight (MSW) with respect to the control treatment in both radiation (Rn: natural radiation; Rs: shading) and pod removal (PR) and defoliation (D) treatments $(n=3)$. 


\section{Yield components correlations}

The variation in yield was mainly explained by changes in seed/ $\mathrm{pl}\left(\mathrm{r}^{2}=0.79, \mathrm{p}<0.001\right)$. Variations in seed/ $\mathrm{pl}$ were explained by variations in pods/ $\mathrm{pl}$ $\left(\mathrm{r}^{2}=0.91, \mathrm{p}<0.001\right)$ without significant association with seed/pod $\left(\mathrm{r}^{2}=0.08, \mathrm{p}>0.1\right)$. MSW was negatively associated with seed/pl $\quad\left(\mathrm{r}^{2}=0.57\right.$, $\mathrm{p}<0.01)$. Although the trend was similar in $\mathrm{Rn}$ $\left(r^{2}=0.82, p<0.001\right)$ and $R s\left(r^{2}=0.81, p<0.001\right)$, the points of MSW corresponding to the Rs were consistently lighter in respect to those of the $\mathrm{Rn}$ treatment. Thus, although the rate of reduction in grain weight per increase in seed per plant was similar in both treatments (Rn vs. Rs), MSW was reduced under shading than under control treatments for the same number of seeds/pl. The fact that MSW was lighter in Rs than in $\mathrm{Rn}$ explains the yield reductions for the same seed/pl.

Mean seed weight responses at different positions in the main raceme
Genotype (G), radiation (R), source: sink (SS) and position treatments significantly affected the weight of seeds positioned at different pod positions within the main raceme. The effect of $G$ was similar to that observed in MSW as, with the exception of the lowermost position, Impulse showed the heaviest and Eclipse the lightest seeds. In relation to the position within the raceme, those seeds located in the lowermost and central pod sections were significantly, lighter (3.09 mg/seed) than those placed in the uppermost pods ( $3.29 \mathrm{mg} / \mathrm{seed})$, while the seeds in the middle positions registered intermediate weights (3.14 mg/seed) (Table 2, Fig. 2). The SS treatments similarly affected seed weight independently of the position within the raceme. Thus, PR increased seed weight by $21 \%$ with respect to $\mathrm{C}$ in those seeds placed on lowermost and middle positions, while it increased the weight of the seeds located in the uppermost position onto the raceme by $15 \%$.

Table 2. Effect of source: sink ratio and radiation levels on mean seed weight (mg/ seed) from pods of different positions into the raceme. Different letters within the same genotype, main raceme section and radiation level indicate significant differences $(\mathrm{p}<0.05)$ among treatments.

\begin{tabular}{|c|c|c|c|c|c|c|c|c|c|c|c|}
\hline \multirow{3}{*}{$\begin{array}{l}\text { Main Raceme } \\
\text { Section } \\
\text { Lowermost }\end{array}$} & \multirow{3}{*}{$\begin{array}{c}\begin{array}{c}\text { Radiation } \\
\text { level }\end{array} \\
\mathrm{Rn} \\
\end{array}$} & \multirow{3}{*}{$\begin{array}{c}\text { Treatments } \\
\mathrm{C} \\
\end{array}$} & \multicolumn{9}{|c|}{ Genotypes } \\
\hline & & & \multicolumn{3}{|c|}{ Eclipse } & \multicolumn{3}{|c|}{ Impulse } & \multicolumn{3}{|c|}{ Master } \\
\hline & & & 2.74 & \pm & $0.06 \mathrm{~b}$ & 3.13 & \pm & $0.06 \mathrm{~b}$ & 3.30 & \pm & $0.07 \mathrm{~b}$ \\
\hline & & PR & 3.18 & \pm & $0.13 \mathrm{a}$ & 3.87 & \pm & $0.25 \mathrm{a}$ & 3.93 & \pm & $0.08 \mathrm{a}$ \\
\hline & & $\mathrm{D}$ & 2.98 & \pm & $0.09 \mathrm{a}$ & 3.24 & \pm & $0.08 \mathrm{~b}$ & 3.21 & \pm & $0.10 \mathrm{~b}$ \\
\hline & Rs & $\mathrm{C}$ & 2.36 & \pm & $0.07 \mathrm{~b}$ & 2.79 & \pm & $0.06 \mathrm{~b}$ & 2.82 & \pm & $0.14 \mathrm{~b}$ \\
\hline & & $\mathrm{PR}$ & 2.88 & \pm & $0.05 a$ & 3.58 & \pm & $0.18 \mathrm{a}$ & 3.38 & \pm & $0.10 \mathrm{a}$ \\
\hline & & $\mathrm{D}$ & 2.47 & \pm & $0.10 \mathrm{~b}$ & 2.82 & \pm & $0.04 \mathrm{~b}$ & 2.92 & \pm & $0.08 \mathrm{~b}$ \\
\hline \multirow[t]{6}{*}{ Middle } & $\mathrm{Rn}$ & $\mathrm{C}$ & 2.72 & \pm & $0.04 \mathrm{~b}$ & 3.28 & \pm & $0.10 \mathrm{~b}$ & 3.23 & \pm & $0.14 \mathrm{~b}$ \\
\hline & & $\mathrm{PR}$ & 3.20 & \pm & $0.07 \mathrm{a}$ & 4.26 & \pm & $0.36 \mathrm{a}$ & 3.94 & \pm & $0.04 \mathrm{a}$ \\
\hline & & $\mathrm{D}$ & 2.80 & \pm & $0.14 \mathrm{~b}$ & 3.33 & \pm & $0.07 \mathrm{~b}$ & 3.09 & \pm & $0.10 \mathrm{~b}$ \\
\hline & Rs & $\mathrm{C}$ & 2.47 & \pm & $0.06 \mathrm{~b}$ & 3.00 & \pm & $0.08 \mathrm{~b}$ & 2.93 & \pm & $0.10 \mathrm{~b}$ \\
\hline & & PR & 2.87 & \pm & $0.12 \mathrm{a}$ & 3.77 & \pm & $0.19 a$ & 3.33 & \pm & $0.11 \mathrm{a}$ \\
\hline & & $\mathrm{D}$ & 2.38 & \pm & $0.07 \mathrm{~b}$ & 2.88 & \pm & $0.02 \mathrm{~b}$ & 2.95 & \pm & $0.11 \mathrm{~b}$ \\
\hline \multirow[t]{6}{*}{ Uppermost } & $\mathrm{Rn}$ & $\mathrm{C}$ & 2.80 & \pm & $0.08 \mathrm{c}$ & 3.49 & \pm & $0.15 \mathrm{~b}$ & 3.56 & \pm & $0,23 \mathrm{~b}$ \\
\hline & & PR & 3.38 & \pm & $0.07 a$ & 4.21 & \pm & $0.39 \mathrm{a}$ & 4.02 & \pm & $0,13 a$ \\
\hline & & $\mathrm{D}$ & 2.97 & \pm & $0.02 \mathrm{~b}$ & 3.51 & \pm & $0.10 \mathrm{~b}$ & 3.35 & \pm & $0,07 \mathrm{~b}$ \\
\hline & Rs & $\mathrm{C}$ & 2.75 & \pm & $0.09 \mathrm{~b}$ & 3.29 & \pm & $0.11 \mathrm{ab}$ & 3.12 & \pm & $0,16 \mathrm{~b}$ \\
\hline & & PR & 3.21 & \pm & $0.10 \mathrm{a}$ & 3.45 & \pm & $0.44 \mathrm{a}$ & 3.62 & \pm & $0,16 \mathrm{a}$ \\
\hline & & $\mathrm{D}$ & 2.61 & \pm & $0.15 \mathrm{~b}$ & 3.12 & \pm & $0.13 \mathrm{~b}$ & 2.75 & \pm & $0,19 \mathrm{c}$ \\
\hline \multicolumn{3}{|c|}{ Genotype (G) } & \multicolumn{9}{|c|}{ *** } \\
\hline \multicolumn{3}{|c|}{ Radiation (R) } & \multicolumn{9}{|c|}{ *** } \\
\hline \multicolumn{3}{|c|}{ Treatment $(\mathrm{T})$} & \multicolumn{9}{|c|}{ *** } \\
\hline \multicolumn{3}{|c|}{ Main Raceme Section (P) } & \multicolumn{9}{|c|}{$* * *$} \\
\hline \multicolumn{3}{|c|}{$\mathrm{G} \times \mathrm{R}$} & \multicolumn{9}{|c|}{ NS } \\
\hline \multicolumn{3}{|c|}{ GxT } & \multicolumn{9}{|c|}{ NS } \\
\hline \multicolumn{3}{|c|}{$\mathrm{RxT}$} & \multicolumn{9}{|c|}{ NS } \\
\hline \multicolumn{3}{|c|}{$\mathrm{GxP}$} & \multicolumn{9}{|c|}{$* *$} \\
\hline & $\mathrm{T} \times \mathrm{P}$ & & & & & & $\mathrm{N}$ & & & & \\
\hline & $\mathrm{RxP}$ & & & & & & $\mathrm{N}$ & & & & \\
\hline & $\mathrm{GxT} \times \mathrm{P}$ & & & & & & $\mathrm{N}$ & & & & \\
\hline & GxTxR & & & & & & $\mathrm{N}$ & & & & \\
\hline & $\mathrm{G} \times \mathrm{R} \times \mathrm{P}$ & & & & & & * & & & & \\
\hline & $\mathrm{GxP}$ x & & & & & & $\mathrm{N}$ & & & & \\
\hline & $\mathrm{GxT \times R \times}$ & & & & & & $\mathrm{N}$ & & & & \\
\hline$*, * *, * * *$ & significant a & $05,0.01$ & and & .00 & probabi & level, & espe & ctively. I & nots & gnif & ant \\
\hline
\end{tabular}




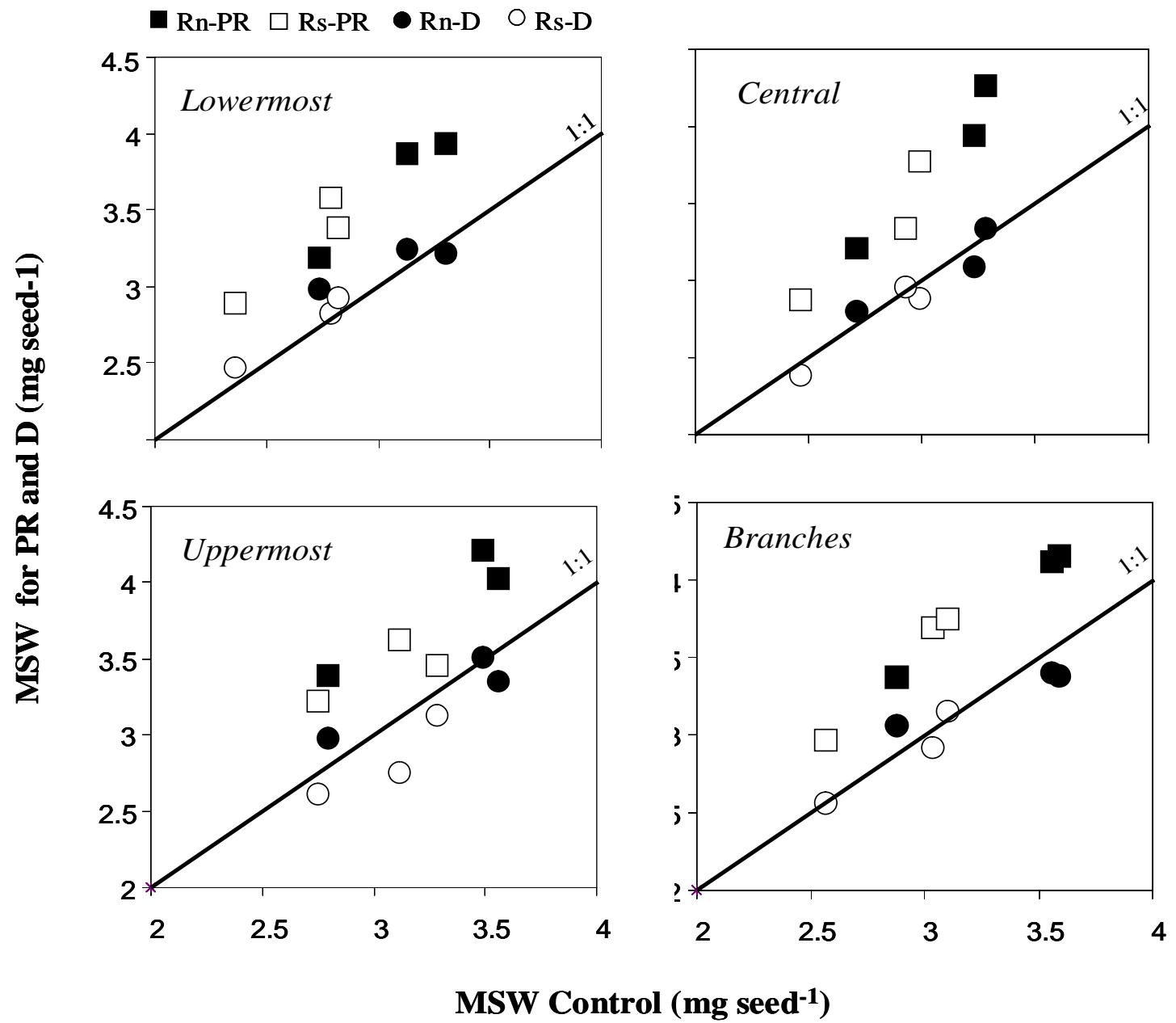

Fig. 2. Mean seed weight (MSW) for pod removal (PR) and defoliation (D) treatments against the control for different seed positions in the main raceme and branches for different radiation (R) and source:sink ratio treatment combinations.

The D treatment did not affect the seed weight when measured in seeds from different position of the raceme and for $\mathrm{R}$ (Table 2). The shadow treatment - Rs-, reduced seed weight ca. by $12 \%$ in respect to $\mathrm{Rn}$, independently of the seed positions into the raceme (Table 2).

Similarly, to what was observed for MSW, the weight of seeds for different pods positions into the raceme showed a negative relationship when plotted against the number of seeds per plant corresponding to each position (Fig. 3). In general, no differences were detected in the slopes between the three sections and for all genotypes studied (data not shown). However, the slope for the uppermost seeds presented slight differences between Rn and Rs in Eclipse and Impulse, but not in Master. In contrast, middle and lowermost sections presented significant differences in the intercepts across Rn and Rs (data not shown), particularly for Eclipse and Impulse, although not so for Master (Fig. 3).

\section{Seed growth dynamics}

When dry weight dynamics of seeds for the applied treatments (G, R and SS) and pod positions were plotted against time, the points were fitted by a bi-linear model (see equation 1), showing coefficients of determination greater than 0.96 in all cases. The bi-linear model allowed the calculation of the rate of seed filling (SGR), total (TSFP) and effective (ESFP) duration of seed filling, and the maximum grain weight obtained in each seed position. Significant differences in the SGR were found for different treatments. When genotypes were compared, the SGR followed the same trend as MSW since SGR was higher in Impulse $(0.00627$ $\left.\mathrm{mg} /{ }^{\circ} \mathrm{Cd}\right)$, followed by Master $\left(0.00615 \mathrm{mg} /{ }^{\circ} \mathrm{Cd}\right)$ and Eclipse $\left(0.00602 \mathrm{mg} /{ }^{\circ} \mathrm{Cd}\right) . \mathrm{PR}$, in line with that occurred in MSW, increased the SGR ca. by $16 \%$, showing the uppermost seed positions the highest increases (i.e. 24\%) when compared with C. Conversely, D did not affect SGR. Rs reduced SGR ca. by $14 \%$ in comparison to Rn, mostly 
affecting the seeds from the central (19\%) and lowermost (15\%) pod positions, while only slight reduction in Rs was observed in seeds from the uppermost positions (6\%) (data not shown). TSFP and ESFP were slightly affected by the treatments. The largest difference in TSFP and ESFP among genotypes was ca. $40{ }^{\circ} \mathrm{Cd}$, which represents approximately 4 days under the environmental conditions of the experiment. Radiation and source-sink treatments almost did not affect the duration of grain filling. Regardless of pod position along the raceme, variations in MSW were most closely related to variations in SGR (P $<0.01)$ rather than to ESFP for all genotypes. Eclipse and Impulse showed the best fit compared to Master (Fig. 4).

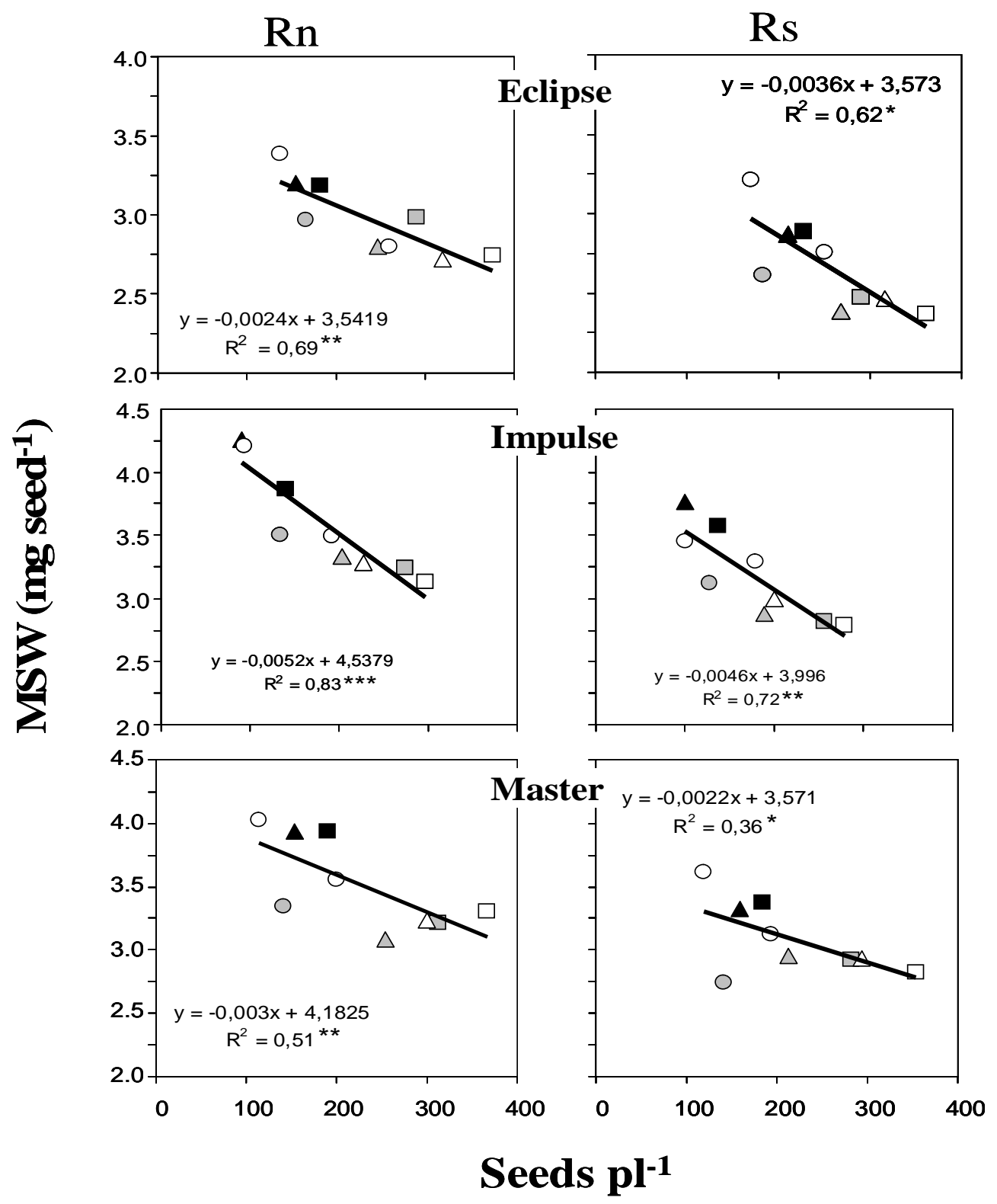

Fig. 3. Relationship between mean seed weight (MSW) and seed per plant for two radiation conditions across different positions in the main raceme and branches. 
C-Rn』Rn-PR』 Rn-D $\triangle \mathrm{C}-\mathrm{Rs}$ a Rs-PR oRs-D
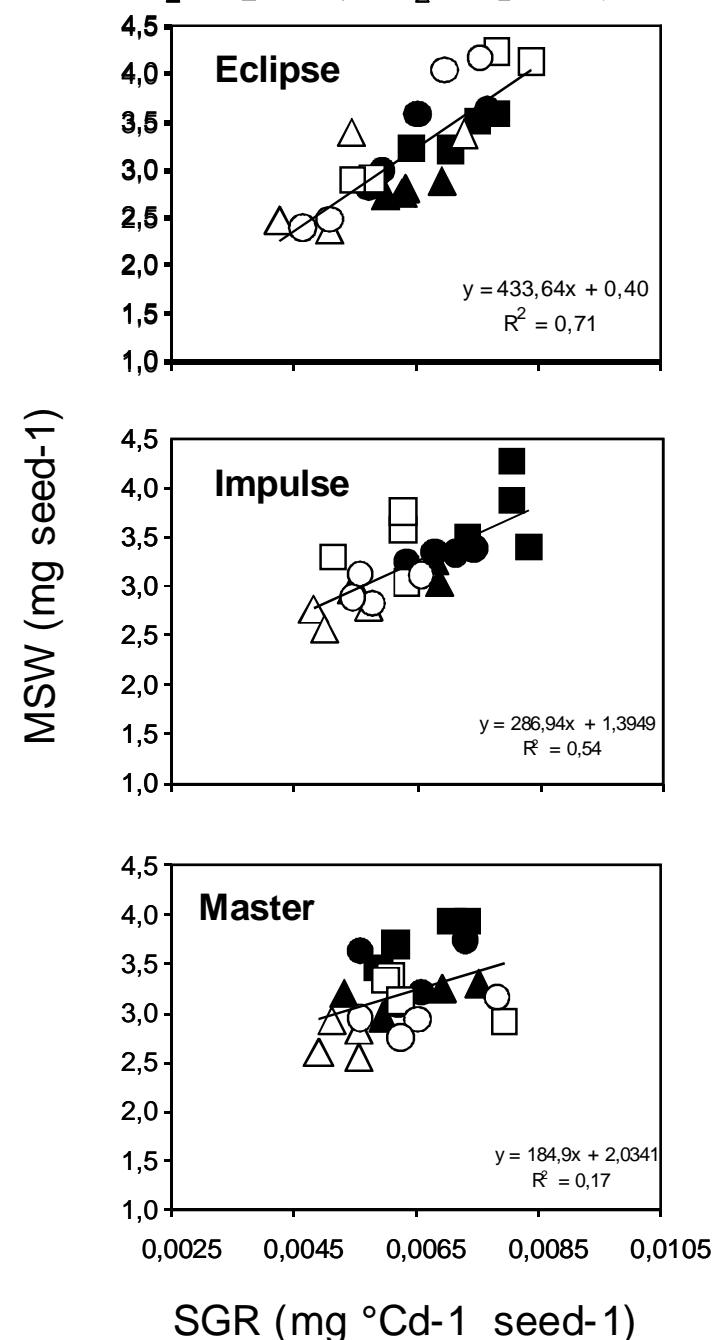
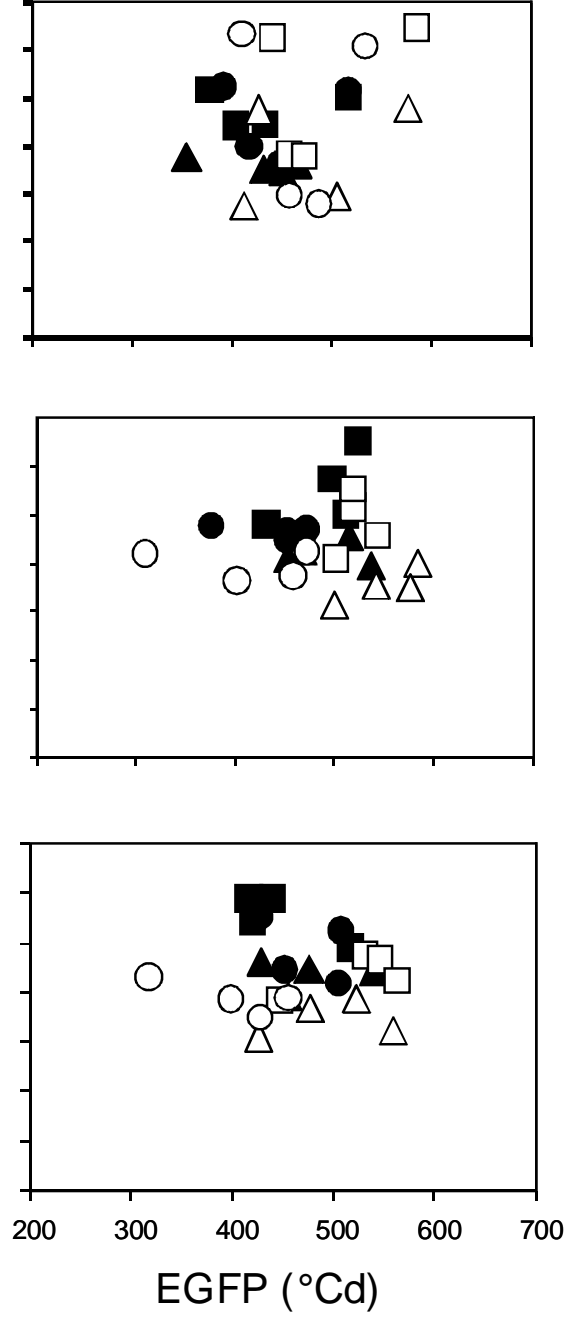

Fig. 4. Relationship between mean seed weight (MSW) and seed growth rate (SGR), and effective seed filling period (ESFP) across radiation conditions and source: sink treatments.

\section{Discussion}

As in many other crops, including cereals and oilseed, the variations in yield were associated with changes in the number of seeds set in the plant rather than with changes in mean seed weight (Egli, 1998; Habekotté, 1993). As reported in soybean (Gomez and Miralles, 2011), the number of seeds per plant was explained by variations in the number of pods per plant since the number of seeds per pod, although more variable in oilseed rape than in soybean, did not explain the changes in seeds per plant. Applying a simplistic and linear reasoning, the negative relationship between MSW and seeds/pl suggests a source limitation to fulfill the grains previously produced. The fact that in the present study MSW was (i) increased by $19 \%$ when sink was reduced ca. $40 \%$ and (ii) the lack of effects on seed weight when source was diminished by defoliation suggests that even when there was response to seed weight when source was increased, there was not a complete limitation for assimilates. Borrás et al. (2004), taking several data from the published literature, showed that wheat was a crop mostly limited by sink as grain weight was not affected by changes in source: sink manipulation; while soybean and maize evidenced source limitation. The results of the present study suggest that oilseed rape presents an intermediate behavior between wheat and maize, as when source per seed was doubled (assuming the most simplistic approach), seeds rose to a half of those increases, suggesting a source:sink co-limitation, similar to that proposed in wheat by Miralles and Slafer (2007).

No differences in individual seed mass was found by defoliation treatments in both radiation level (Rn and Rs) when compared to C, particularly in 
pods developed later. This would be explained by two ways. First, in the most source: sink restrictive combination (Rs-D), $10 \%$ reductions in the number of seeds per pod was produced (Table 1), in turn; fewer seeds in the upper pods were exposed to more assimilate with respect to the $\mathrm{C}$. An opposite situation was observed for seeds from branches (data not shown). The slight, but significant, increase in the number of seeds per pod, originated by the pod removal treatment produced in the three genotypes, can be related to assimilate and/or phytohormone stimulation. In oilseed rape, the flowering period is sequential and proceeds from basal to upper positions in main raceme. Therefore, by the time of treatment application upper pods were at an early stage of development and thereby were probably more susceptible to abortion than the peripheral ones (Keiller and Morgan, 1988; Leterme, 1988). The strong overlap of pod formation, seed set and seed filling periods allowed Rs or PR from the beginning of seed filling to have a strong impact on the number of seeds per pod.

Second, the lack of change in MSW when D was applied implicates that an important part of photoassimilates remobilized during seed filling comes from pods and stems. Therefore, in this situation, remobilization would sustain the growth of the seeds without any change produced in MSW. In a previous report, Habekotté (1993) showed that the level of carbohydrates at the end of seed fill represents ca. $20 \%$ of the carbohydrates level accumulated at the end of flowering. By contrast, Quilleré and Triboi (1987) described a contribution of remobilization to seed yield of $17.5 \%$, at the most, in only one variety.

The degree of response observed in MSW when source per seed was increased, especially for those seeds set later on the flowering period (middle and uppermost pods), could also be attributed to changes in the potential sizes of the seeds. Thus, the earlier the manipulation, the higher the response with respect to control, as seed weight potential was expected to be more affected by source: sink manipulations when endospermatic cells and ovary size were growing (Lizana et al., 2010).

The analysis of the physiological components of seed growth indicated that the causes of the changes in seed weight by source: sink modifications were related to modifications in SGR rather than in ESFP, as suggested by Habekotté (1993), who reported reductions in SGR in oilseed rape as a result of shading treatments imposed around mid-flowering. Additional evidence for several other species showed that the final individual seed weight was largely correlated to the seed growth rate rather than to changes in seed filling duration (Miralles and Slafer, 1995; Alvarez-Prado et al., 2013).

Although the general pattern for explaining the variations in MSW consisted of changes in SGR, rather than in ESFP, a different response pattern observed when seeds from pods of different sections analyzed. The highest response to sink reduction in MSW, when compared to $\mathrm{C}$ in relative terms, observed in the lower and middle pod positions onto the raceme. However, the highest response in SGR corresponded to the grains places in pods of the uppermost position. An explanation for this may be related with the fact that at the time of treatment manipulation, ca. $350{ }^{\circ} \mathrm{Cd}$ ( $\sim 20$ days after onset of flowering), it might be possible that basal and middle pods were close to the beginning of the linear phase of growth, unlike the upper ones, which were initiating the seed growth i.e. lag phase. MunierJolain and Salon (2003) suggested that sucrose, together with endogenous phytohormones level during the embryo cell division phase, could determine its mitotic activity by modulating the expression of genes that participate in the cell cycle regulation. Therefore, if this is the case, when cell division starts in basal and middle pods of the raceme, competition for assimilates is low, as few pods are undergoing cell division. Hence, competition for assimilates supply increases in the reproductive tissues of basal and middle sections of the main raceme generating, in consequence, a restriction of assimilates and/ or growth regulators in the upper section of the main raceme and of the branches, thereby limiting their cell division rate and growth.

\section{Acknowledgments}

We gratefully acknowledge financial support from FONCYT (Science and Technology Fund, Argentina)

\section{References}

Alvarez Prado, S., Gallardo, J.M., Serrago, R.A., Kruk, B.C. and Miralles, D.J. 2013. Comparative behavior of wheat and barley associated with field release and grain weight determination. Field Crops Res. 144: 28-33.

Berry, P.M. and Spink, J.H. 2006. A physiological analysis of oilseed rape yields: past and future. J. Agric. Sci. 144: 381- 392.

Borrás, L., Slafer, G.A. and Otegui, M.E. 2004. Seed dry weight response to source-sink manipulations in wheat, maize and soybean: a quantitative reappraisal. Field Crops Res. 86: 131-146.

Diepenbrock, W. 2000. Yield analysis of winter oilseed rape (Brassica napus L.): a review. Field Crops Res. 67: 35-49. 
Egli, D.B. 1998. Seed biology and the yield of grain crops. Cab International, Wallington, UK. p. 178.

Gabrielle, B., Denoroy, P., Gosse, G., Justes, E. and Andersen, M.N. 1998. A model of leaf area development and senescence of winter oilseed rape. Field Crops Res. 57: 209-222.

Gomez, N.V. and Miralles D.J. 2011. Factors that modify early and late reproductive phases in oilseed rape (Brassica napus L.): Its impact on seed yield and oil content. Industrial Crops and Products 34: 1277-1285

Habekotté, A. 1993. Quantitative analysis of pod formation, seed set and seed filling in winter oilseed rape (Brassica napus L.) under field conditions. Field Crops Res. 35: 21-33.

J andel Scientific, 1992. Tbl curve fitting software. Version 3.0. Corte Madera USA: Jandel Scietific.

J enner, C.F., Ugalde, T.D. and Aspinall, D. 1991. The physiology of starch and protein deposition in the endosperm of wheat. Aust. J. Plant Physiol. 18: 211- 226.

Jullien, A., Mathieu, A., Allirand, J.M., Pinet, A., de Reffye, P., Cournède, P.H. and Ney, B. 2011. Characterization of the interactions between architecture and source: sink relationships in winter oilseed rape (Brassica napus) using the GreenLab model. Ann. Bot. 107: 765-779.

Keiller, D.R. and Morgan, D.G. 1988. Distribution of 14carbon-labelled assimilates in flowering plants of oilseed rape (Brassica napus L.). J. Agric. Sci. 111: 347- 355.

Leach, J.E., Milford, G.F.J., Mullen, L.A., Scott, T. and Stevenson, H.J. 1989. Accumulation of dry matter in oilseed rape crops in relation to the reflection and absorption of solar radiation by different canopy structures. Aspects Appl. Biol. 23: 117-123.

Leterme, P. 1988. Croissance et développement du colza d'hiver: Les principales étapes. in: Cetiom (eds.), colza-physiologie et elaboration du rendement du colza d'hiver. Suppl. Inf. Techn. CETIOM, pp. 23-33.
Lizana, X. C., Riegel, R., Gomez, L.G., Herrera, J., Isla, A., McQueen-Mason, S.J. and Calderini, D.F. 2010. Expansins expression is associated with grain size dynamics in wheat (Triticum aestivum L). J. Exp. Bot. 61: 1147-1157.

Mendham, N.J., Shipway, P.A., and Scott R.K. 1981. The effects of delayed sowing and weather on growth, development and yield of winter oil-seed rape (Brassica napus). J . Agril. Sci. 96: 389-416.

Miralles, D.J. and Slafer, G.A. 1995. Individual grain weight responses to genetic reduction in culm length in wheat as affected by source-sink manipulations. Field Crops Res. 43: 55-66.

Miralles, D.J. and Slafer, G.A. 2007. Sink limitations to yield in wheat: how could it be reduced?. J . Agril. Sci. 145: 139-149.

Müller, J. and Diepenbrock, W. 2006. Measurement and modelling of gas exchange of leaves and pods of oilseed rape. Agril. and Forest Meteor. 139: 307-3221.

Munier-Jolain, N. and Salon, C. 2003 Can sucrose content in the phloem sap reaching field pea seeds (Pisum sativum L.) be an accurate indicator of seed growth potential? J. Exp. Bot. 54: 2457-2465.

Pechan, P.M. and Morgan, D.G. 1985. Defoliation and its effects on pod and seed development in oil seed rape (Brassica napus L.). J . Exp. Bot. 36: 458-468.

Peltonen-Sainio, P. and J auhiaine or J auhiainen, L. 2008. Association of grouth dynamics, yield components and seed quality in longterm trials covering rapeseed cultivation history at high latitudes. Field Crops Res. 108: 101-108.

Quilleré, I. and Triboi, A.M. 1987. Dynamique des reserves carbonée chez le colza d'hiver: Impacts sur la crossance. 7, pp. 219-223.

Yates, D.J. and Steven, M.D. 1987. Reflexion and absorption of solar radiation by flowering canopies of oil-seed rape (Brassica napus L.). J. Agric. Sci. 109: 495-502. 